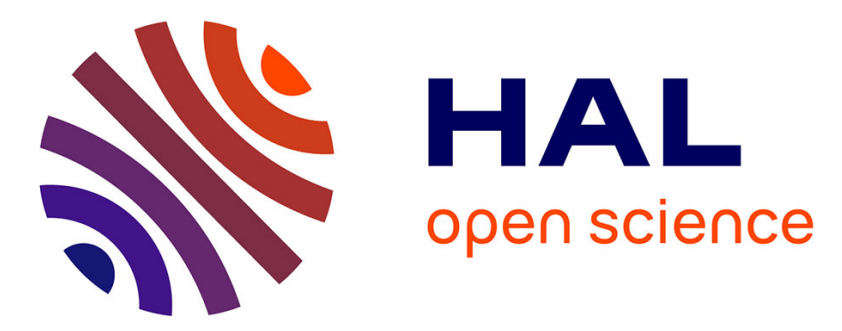

\title{
$18 \mathrm{O}(\mathrm{p}, \alpha) 15 \mathrm{~N}$ isotopic tracing of germanium diffusion in $\mathrm{SiO} 2 / \mathrm{Si}$ films
}

\author{
A. Nélis, Ian Vickridge, J.-J. Ganem, E. Briand, G. Terwagne
}

\section{To cite this version:}

A. Nélis, Ian Vickridge, J.-J. Ganem, E. Briand, G. Terwagne. $18 \mathrm{O}(\mathrm{p}, \alpha) 15 \mathrm{~N}$ isotopic tracing of germanium diffusion in SiO2/Si films. Journal of Applied Physics, 2021, 130 (10), pp.105701. $10.1063 / 5.0057968$. hal-03453694

\section{HAL Id: hal-03453694 \\ https://hal.science/hal-03453694}

Submitted on 29 Nov 2021

HAL is a multi-disciplinary open access archive for the deposit and dissemination of scientific research documents, whether they are published or not. The documents may come from teaching and research institutions in France or abroad, or from public or private research centers.
L'archive ouverte pluridisciplinaire HAL, est destinée au dépôt et à la diffusion de documents scientifiques de niveau recherche, publiés ou non, émanant des établissements d'enseignement et de recherche français ou étrangers, des laboratoires publics ou privés. 


\title{
${ }^{18} \mathrm{O}(\mathrm{p}, \alpha){ }^{15} \mathrm{~N}$ isotopic tracing of germanium diffusion in $\mathrm{SiO}_{2} / \mathrm{Si}$ films
}

\author{
A. Nélis ${ }^{1, *}$, I. Vickridge ${ }^{2}$, J.-J. Ganem ${ }^{2}$, E. Briand ${ }^{2}$, G. Terwagne ${ }^{1}$ \\ 2021-07-16 \\ ${ }^{1}$ LARN, Namur Institute of Structured Matter (NISM), University of Namur (UNAMUR), B-5000 Namur, \\ Belgium \\ ${ }^{2}$ INSP, UPMC, Univ Paris 6, CNRS UMR758, 140 Rue de Lourmel, 75015 Paris, France
}

\begin{abstract}
We investigate the effects of oxygen on the thermal diffusion of germanium atoms, implanted inside a thermally grown $\mathrm{SiO}_{2}$ layer, during high temperature processes $\left(1100^{\circ} \mathrm{C}, 60\right.$ minutes $)$. The impact of oxygen presence on Ge diffusion is studied as a function of its origin, as it can come either from the annealing atmosphere (extrinsic source) or from the $\mathrm{SiO}_{2}$ matrix itself (intrinsic source). ${ }^{18} \mathrm{O}$ labeling of the oxygen either in the annealing atmosphere or in the silica substrate, together with isotopically sensitive Ion Bean Analysis (IBA), shows a clear oxygendependence in germanium diffusion. This is especially so when oxygen is present in the annealing atmosphere, where it is responsible for an enhancement of germanium out-diffusion and redistribution into several peaks during annealing, through the formation of $\mathrm{GeO}$ molecules. A new three-process is proposed to explain the impact of a contaminated atmosphere on Ge redistribution. This is notably shown that a third Ge peak arises at the sample surface when the annealing atmosphere is contaminated by oxygen. This peak formation is explained by the oxidation of Ge present at the vicinity of the surface by oxygen coming from the annealing atmosphere. This is also shown that $\mathrm{O}_{2}$ molecules can diffuse in depth, with a coefficient of diffusion $\mathrm{D}_{\mathrm{O}_{2}} \sim 10^{-9} \mathrm{~cm}^{2} / \mathrm{s}$, until the densities of Ge and irradiation-induced defects increase, causing the progressive oxidation of $\mathrm{Ge}$ in depth and the restoration of the $\mathrm{SiO}_{2}$ stoichiometry.
\end{abstract}

\footnotetext{
* Corresponding author: adrien.nelis@unamur.be
} 
Keywords: Resonant Nuclear Reaction Analysis; Ge diffusion; ion implantation; GeO formation; stable isotopic tracing.

\section{Introduction}

Integration of germanium nanocrystals (Ge-ncs), and more widely group IV materials, produced by ion implantation into dielectric layers has been largely studied over last decades thanks to their numerous attractive optoelectronic properties [1-5]. Bandgap engineering, possible multiple exciton generation (MEG) or photoluminescence show great promise for enhancing the conversion efficiency of modern photovoltaic cells.

Fabrication of Ge-ncs by ion implantation requires a thermal activation, with temperatures as high as $800-1100^{\circ} \mathrm{C}$ under non-reactive atmosphere $\left(\mathrm{N}_{2}\right.$ or Ar), which is responsible for longrange germanium redistribution inside the insulator layer, a thermally grown silicon dioxide film in this study [6-14]. Germanium diffusion mechanisms are generally associated in literature to the presence of oxygen $[8-13,15,16]$. The first origin of the oxygen involved in germanium diffusion is the oxygen directly supplied by the $\mathrm{SiO}_{2}$ host matrix and released by the dose-dependent damage and atomic rearrangement generated during the implantation and annealing processes. X-ray photoelectron spectroscopy (XPS) measurements demonstrated that implanted germanium ions are chemically bound to oxygen and silicon atoms present in the $\mathrm{SiO}_{2}$ layer, already during the implantation process $[9,12,17]$. This is responsible for the formation of $\mathrm{GeO}_{\mathrm{x}}$ compounds within the oxide film, including highly volatile $\mathrm{GeO}$, considered to be the main contributor to germanium out-diffusion during thermal treatments. Heinig et al. (11) and Borodin et al. [18] also proposed that oxygen could be provided by the presence, in the annealing atmosphere, of residual moisture and other oxygen-containing compounds $\left(\mathrm{O}_{2}\right.$, $\left.\mathrm{H}_{2} \mathrm{O}, \mathrm{OH}\right)$. These oxidizing agents could penetrate through the damaged silica surface and diffuse inside the $\mathrm{SiO}_{2}$ film. 
In this work, we propose to use the ${ }^{18} \mathrm{O}$ isotope to trace oxygen behavior during thermal processes and to correlate it with the diffusion of implanted germanium atoms. Two sets of samples have been prepared. The first set of samples aims to highlight the transport of oxygen atoms originating in the $\mathrm{SiO}_{2}$ layer, by using an ${ }^{18} \mathrm{O}$-containing oxide film implanted with $\mathrm{Ge}$ and annealed under high purity $\mathrm{N}_{2}$ atmosphere (100\% of the gas introduced in the furnace tube). The second set of samples is intended to show the impact of oxidizing agents present in the annealing environment on the diffusion of germanium by using commercial thermallygrown $\mathrm{SiO}_{2}$ layers implanted with germanium and annealed under a controlled atmosphere composed of $99 \%$ of nitrogen and $1 \%$ of ${ }^{18} \mathrm{O}_{2}$. This allows us to highlight the impact of the purity of the annealing environment on the germanium redistribution.

${ }^{74} \mathrm{Ge}$ and ${ }^{18} \mathrm{O}$ depth-distributions before and after annealing are obtained by a combination of Rutherford Backscattering Spectroscopy (RBS), Nuclear Reaction Analysis (NRA) and Resonant Nuclear Reaction Analysis (RNRA) measurements.

\section{Experiment}

The two sets of samples will be referred as type $\mathrm{A}$, for Ge implantations in $\mathrm{Si}^{18} \mathrm{O}_{2}$ layers (sandwiched between two $\mathrm{Si}^{16} \mathrm{O}_{2}$ layers - see below) annealed under pure $\mathrm{N}_{2}$ (after the implantation), and type $\mathrm{B}$, for Ge implantations in commercial $\mathrm{SiO}_{2}$ films annealed under an atmosphere contaminated by ${ }^{18} \mathrm{O}_{2}$ molecules.

For type A samples, (100) silicon wafers are oxidized before Ge implantation under dry atmosphere in three successive steps $\left({ }^{16} \mathrm{O} /{ }^{18} \mathrm{O} /{ }^{16} \mathrm{O}\right)$ to obtain a sandwich configuration. The respective thicknesses of the three layers (from the sample surface to depth), confirmed by RBS, were: 1. $\sim 110 \mathrm{~nm} \mathrm{Si}^{16} \mathrm{O}_{2} ; 2$. $\sim 60 \mathrm{~nm} \mathrm{Si}^{18} \mathrm{O}_{2} ; 3$. $\sim 80 \mathrm{~nm} \mathrm{Si}^{16} \mathrm{O}_{2}$. They were chosen so that the projected range $\mathrm{R}_{\mathrm{p}}$ of about $134 \mathrm{~nm}$ (calculated by SRIM-2013 [19]) for the ${ }^{74} \mathrm{Ge}^{+}$ions implanted at $185 \mathrm{keV}$ is located around the middle of the ${ }^{18} \mathrm{O}$ labelled layer. After implantation, samples were annealed at $1100^{\circ} \mathrm{C}$ for 60 minutes in pure $\mathrm{N}_{2}(600 \mathrm{mbar})$ in a quartz tube furnace 
(INSP), coupled with a turbomolecular pump. Base pressure in the furnace before introduction of $\mathrm{N}_{2}$ was $<10^{-5}$ mbar.

For type B samples, $300 \mathrm{~nm}$ thick wet-oxidized and $200 \mathrm{~nm}$ dry-oxidized (100) silicon wafers were implanted with ${ }^{74} \mathrm{Ge}^{+}$ions at energies of $230 \mathrm{keV}\left(\mathrm{R}_{\mathrm{p}}=156 \mathrm{~nm}\right)$ and $140 \mathrm{keV}\left(\mathrm{R}_{\mathrm{p}}=156\right.$ $\mathrm{nm}$ ) respectively, for measured fluences varying from $3.5 \times 10^{16}$ to $2.2 \times 10^{17} \mathrm{Ge} / \mathrm{cm}^{2}$. After implantation, the samples are annealed at $1100^{\circ} \mathrm{C}$ for 60 minutes under a controlled atmosphere of 594 mbar $\mathrm{N}_{2}$ plus 6 mbar ${ }^{18} \mathrm{O}_{2}$ in INSP quartz tube furnace. Note that anneals just in 6 mbar ${ }^{18} \mathrm{O}_{2}$ without nitrogen gives very similar results, with a weak quantity of additional oxygen incorporated in the presence of nitrogen)

All implantations were carried out with the 2 MV Tandetron ALTAÏS (Accélérateur Linéaire Tandetron pour l'Analyse et l'Implantation des Solides) accelerator available at LARN.

${ }^{74} \mathrm{Ge}$ fluences and depth-profiles were verified by RBS before and after annealing at INSP with the 2.5 MV Van de Graaff accelerator of SAFIR platform (System d'Analyses par Fasceaux d'Ions Rapides) or at LARN with ALTAÏS.

${ }^{18} \mathrm{O}$ depth-profiles were measured via the ${ }^{18} \mathrm{O}(\mathrm{p}, \alpha){ }^{15} \mathrm{~N}$ narrow resonant reaction (width $\Gamma \sim 100$ $\mathrm{eV})$ at $151 \mathrm{keV}$ [20-23]. The ${ }^{18} \mathrm{O}$ depth-profiles are deduced from the measured excitation curves by iteratively fitting simulations generated by SPACES [24], assuming a stopping power and a density of $475 \mathrm{keV} /\left(\mu \mathrm{g} / \mathrm{cm}^{2}\right)$ and $6.65 \times 10^{22} \mathrm{at} / \mathrm{cm}^{3}$ respectively for pure $\mathrm{SiO}_{2}$.

${ }^{16} \mathrm{O}$ and ${ }^{18} \mathrm{O}$ were quantified by NRA before and after annealing, with ${ }^{16} \mathrm{O}(\mathrm{d}, \alpha){ }^{14} \mathrm{~N}$ and ${ }^{18} \mathrm{O}(\mathrm{d}, \alpha){ }^{16} \mathrm{~N}$ reactions at 860 and $750 \mathrm{keV}$.

\section{Results and discussion}

\subsection{Annealing under pure $\mathrm{N}_{2}$ : role of the host matrix}

The isotopic sandwich structure of the implanted oxide is visible in figure 1 , showing the ${ }^{18} \mathrm{O}$ 
depth-profile of a virgin $\left[\mathrm{Si}^{16} \mathrm{O}_{2} / \mathrm{Si}^{18} \mathrm{O}_{2} / \mathrm{Si}^{16} \mathrm{O}_{2}\right]$ oxide layer represented by a black solid line. The $\mathrm{Si}^{18} \mathrm{O}_{2}$ film is centered at around $130 \mathrm{~nm}$, almost corresponding to the middle of the whole oxide, with a small peak at the sample surface, resulting from ${ }^{18} \mathrm{O} /{ }^{16} \mathrm{O}$ exchanges taking place during the successive oxidation steps [25].

As shown in figure 1 for three different germanium fluences, the oxide layer undergoes a significant atomic rearrangement during implantation due to recoiled $\mathrm{Si}$ and $\mathrm{O}$ atoms, and subsequent cascades of collisions, caused by the passage of heavy ${ }^{74} \mathrm{Ge}^{+}$ions. The beam effect is visible by observing the ${ }^{18} \mathrm{O}$ depth-distribution of the buried $\mathrm{Si}^{18} \mathrm{O}_{2}$ layer, showing substantial disorganization of the oxide film for the higher fluence $\left(2.6 \times 10^{17} \mathrm{Ge} / \mathrm{cm}^{2}\right.$ - dotted line $)$. This layer rearrangement is consistent with the changes in the $\mathrm{SiO}_{2}$ stoichiometry calculated by Tridyn simulations in ref. [9]. This dose-dependent atomic rearrangement leads to large stoichiometric discrepancies throughout the $\mathrm{SiO}_{2}$ film, resulting in silicon excess (with respect to stoichiometric $\mathrm{SiO}_{2}$ ) between the sample surface and the Ge projected range, and oxygen excess behind the projected range of germanium (see RBS results in figure S1 in supplementary material and more details in the upcoming ref. [17]). As a significant number of Si-O bonds are broken by the passage of the ${ }^{74} \mathrm{Ge}^{+}$ions, a high fraction of ${ }^{74} \mathrm{Ge}^{+}$ions will chemically bind to $\mathrm{Si}$ or $\mathrm{O}$ during the implantation. The concentrations of $\mathrm{Ge}-\mathrm{Si}$ and $\mathrm{Ge}-\mathrm{O}$ bonds increase with germanium fluence, as well as the formation of Ge-Ge bonds [17] (see figure S2 in supplementary material). Ge chemically bound to germanium or silicon is poorly mobile. The presence of germanium in an oxidised state after the implantation step has been largely observed in literature $[9,12,17,26]$. Among $\mathrm{GeO}_{\mathrm{x}}$ compounds, highly volatile $\mathrm{GeO}$ molecules are formed. These are generally considered to be the main mobile species responsible of both germanium diffusion and desorption.

As shown in figure 2, after implantation both $\mathrm{Ge}$ and ${ }^{18} \mathrm{O}$ profiles practically overlap (black dots and blue solid line respectively). This allows us to study the migration of these two species 
and highlight a possible connection between their thermally activated diffusion. As germanium atoms locally bind with oxygen atoms to form $\mathrm{GeO}_{\mathrm{x}}$, a fraction of implanted ions chemically binds to ${ }^{18} \mathrm{O}$ and ${ }^{16} \mathrm{O}$ during the implantation.

Three implantation fluences of $6.5 \times 10^{16}, 1 \times 10^{17}$ and $1.5 \times 10^{17} \mathrm{Ge} / \mathrm{cm}^{2}$ are shown in figure 2, corresponding to figures $2 \mathrm{a}, 2 \mathrm{~b}$ and $2 \mathrm{c}$ respectively. After annealing under pure $\mathrm{N}_{2}$ atmosphere, Ge exhibits a depth-profile (red triangles) consistent with that of samples annealed under pure $\mathrm{N}_{2}$ (for an example see ref. [7]), i.e. a double peak configuration with a major peak slightly shifted towards the sample surface and an accumulation of $\mathrm{Ge}$ at the $\mathrm{SiO}_{2} / \mathrm{Si}$ interface. This asymmetric diffusion is generally explained by the introduction of $\mathrm{GeO}$ molecules, diffusing towards oxygen-poor regions such as the sample surface and the $\mathrm{SiO}_{2} / \mathrm{Si}$ interface $[8,9,11,17,27]$. The formation of these highly volatile $\mathrm{GeO}$ molecules could also explain $\mathrm{Ge}$ desorption occuring at the sample surface.

We know from previous works that the mobility of Ge is linked to the saturation in oxygen of the $\mathrm{SiO}_{2}$ layer. As the oxide region between Ge projected range and sample surface is understoichiometric $\left(\mathrm{SiO}_{\mathrm{x}}, \mathrm{x}<2\right)$, metastable $\mathrm{GeO}_{\mathrm{x}}$ will reduce in a thermodynamically more stable configuration, while the $\mathrm{SiO}_{2}$ network tends to recover its stoichiometry:

$$
\begin{aligned}
& \mathrm{GeO}+\mathrm{SiO} \rightarrow \mathrm{Ge}+\mathrm{SiO}_{2},[28,29] \\
& \mathrm{GeO}_{x}+\mathrm{Si} \rightarrow \mathrm{Ge}+\mathrm{SiO}_{x},[16] \\
& \mathrm{SiO}_{x} \rightarrow\left(1-\frac{x}{2}\right) \mathrm{Si}+\frac{x}{2} \mathrm{SiO}_{2} \cdot[30]
\end{aligned}
$$

All reactions are supposed to be initiated in the first moments of annealing. As the $\mathrm{SiO}_{2}$ layer recovers its stoichiometry in a region initially presenting a lack of oxygen, the concentration of less mobile elemental $\mathrm{Ge}$ and $\mathrm{Si}$ increases, leading to the local formation of $\mathrm{Ge}$ and $\mathrm{SiGe}$ nanocrystals. As the coefficient of diffusion of Ge is two orders of magnitude higher than that 
of $\mathrm{Si}$ in $\mathrm{SiO}_{2}$ [27], mostly $\mathrm{Ge}-\mathrm{Si}$ and Ge-Ge chemical bonds will be formed rather than $\mathrm{Si}-\mathrm{Si}$ $[6,7,31]$. The chemical evolution of the main RBS peak has been probed by XPS studies $[16,17]$, confirming that $\mathrm{GeO}_{\mathrm{x}}$ is reduced to elemental $\mathrm{Ge}^{0}$ during annealing (i.e. Ge chemically bound to $\mathrm{Ge}$ or $\mathrm{Si}$, which are not distinguishable by XPS). Only germanium implanted close to the surface is eventually able to desorb through the gas/oxide interface before being trapped by the nucleation process.

On the other side, a Ge accumulation peak is measured at the $\mathrm{SiO}_{2} / \mathrm{Si}$ interface, indicating that a part of germanium diffuses inwards. Due to the over-stoichiometric state $\left(\mathrm{SiO}_{\mathrm{x}}, \mathrm{x}>2\right)$ of the oxide region between the Ge projected range and the $\mathrm{Si}$ substrate after implantation, the reduction process of equations 1-3 will restore the $\mathrm{SiO}_{2}$ stoichiometry while probably maintaining a mixture of elemental $\mathrm{Ge}$ and $\mathrm{GeO}_{\mathrm{x}}$ compounds less likely to be trapped by $\mathrm{Si}$ dangling bonds because of oxygen excess. RBS analyses confirm that Ge mobility is greater in the second half of the Ge depth-profile, as it is this part of the profile which is redistributed during annealing.

The ${ }^{18} \mathrm{O}$ depth-profile after annealing (dashed blue lines) also shows an asymmetric diffusion, whose range is limited to a few nanometers towards the sample surface but is, on the other hand, able to reach the $\mathrm{SiO}_{2} / \mathrm{Si}$ interface. This is consistent with the stoichiometric discrepancies previously mentioned, with a high rate of interactions of diffusing species with understoichiometric $\mathrm{SiO}_{\mathrm{x}}(\mathrm{x}<2)$ between the Ge projected range and the sample surface, which acts as a trapping center for $\mathrm{GeO}_{\mathrm{x}}(0 \leq \mathrm{x}<2)$ or oxygen, and with over-stoichiometric $\mathrm{SiO}_{\mathrm{x}}(\mathrm{x}>2)$ towards the $\mathrm{SiO}_{2} / \mathrm{Si}$ interface. Figure 2 shows that annealing perturbs ${ }^{18} \mathrm{O}$ depth-profile more as the Ge fluence increases, with a clear redistribution into two peaks for the sample 2c. As observed by XPS (see figure S2 in supplementay material), these positions correspond to the $\mathrm{SiO}_{2}$ regions where the concentrations of elemental $\mathrm{Ge}$ and $\mathrm{GeO}_{x}$ are maximum after the implantation. These regions seem to be particular centers for oxygen fixation. 
As no real ${ }^{18} \mathrm{O}$ buildup is observed at the $\mathrm{SiO}_{2} / \mathrm{Si}$ interface, it can be deduced that only a very small number of ${ }^{18} \mathrm{O}$ atoms reaches the substrate. Three possible interpretations:

1. The interface peak is due to the diffusion of elemental Ge, whose diffusion in depth is not limited by the presence of silicon dangling bonds.

2. If germanium diffuses under the form of $\mathrm{GeO}_{\mathrm{x}}$ compounds, this indicates that they could exchange or yield their oxygen before reaching the interface:

$$
G e^{18} O_{x}+S i^{16} O_{2} \rightarrow G e^{16} O_{x}+S i^{16(18)} O_{2}
$$

3. The number of Ge atoms chemically bound to ${ }^{18} \mathrm{O}$ is weak, as Ge will probably bind preferentially with recoiled ${ }^{16} \mathrm{O}$ coming from the first 110 nanometers.

Another possibility proposed in literature is the encounter of $\mathrm{GeO}_{\mathrm{x}}$ coming from the implanted zone and $\mathrm{SiO}$ molecules emitted by the substoichiometric interface $[9,15,32]$ :

$$
G e^{18} O_{x}+S i^{16} O \rightarrow G e+S i^{16(18)} O_{1+x}
$$

Knowing that the diffusion coefficient of $\mathrm{SiO}$ molecules is estimated to be $D_{S i O}\left(1100^{\circ} \mathrm{C}\right)=$ $4 \times 10^{-17} \mathrm{~cm}^{2} / s[15]$, this can only occur close to the $\mathrm{SiO}_{2} / \mathrm{Si}$ interface.

In any case, oxidized Ge would be reduced upon reaching the substoichiometric $\mathrm{SiO}_{\mathrm{x}} / \mathrm{Si}$ interface, releasing elemental $\mathrm{Ge}$ atoms in the vicinity of the $\mathrm{SiO}_{2} / \mathrm{Si}$ interface which is free to bond to $\mathrm{Si}$ (mainly) or other Ge atoms. At least a part of this germanium is supposed to penetrate in a shallow layer of the silicon substrate because of the solubility of germanium in silicon due to their similar atomic structure $[8,11]$. This agrees with XPS observations $[12,17]$, indicating the presence of only Ge-Ge and Ge-Si chemical bonds in the vicinity of the interface region. 


\subsection{Annealing under a contaminated environment}

Figure 3 shows Ge depth-profiles extracted from RBS analyses, before and after annealing, for type B samples implanted with different Ge fluences inside $200 \mathrm{~nm}$ (figure 3a) and $300 \mathrm{~nm}$ (figures $3 b-d$ ) $\mathrm{SiO}_{2}$ layers. Figures $3 b-d$ correspond to fluences of $4.5 \times 10^{16}, 1.2 \times 10^{17}$ and 2.2 $\times 10^{17} \mathrm{Ge} / \mathrm{cm}^{2}$ respectively. The fluence $\left(3.5 \times 10^{16} \mathrm{Ge} / \mathrm{cm}^{2}\right)$ of the sample presented in figure 3a has been chosen to get similar concentration at maximum to that in the sample presented in figure $3 b$. The left side of figures $3 a-d$ corresponds to the sample surface.

For each germanium fluence, the Ge depth-profile after annealing (red triangles in figure 3) is redistributed into three peaks, with the emergence of a subsurface peak (peak 1) that was not observed for annealing under pure nitrogen (figure 2). This three-peaks configuration, which is frequently observed in the literature $[8,10-12,17]$, is generally associated with the presence of oxygen in the annealing atmosphere.

As peak 1 is not present for annealing under pure $\mathrm{N}_{2}$, this peak can be directly associated with the presence of oxygen in the annealing environment. Peaks 2 and 3 are similar to those observed in figure 2, corresponding to a Ge diffusion mainly directed towards the sample surface and a Ge accumulation at the $\mathrm{SiO}_{2} / \mathrm{Si}$ interface, but with a clear enhancement of outward diffusion for the intentionally contaminated atmosphere.

First of all, it can be inferred from NRA measurements (figure 4) that ${ }^{18} \mathrm{O}$ incorporation during annealing is not due only to ${ }^{16} \mathrm{O} /{ }^{18} \mathrm{O}$ surface exchanges, since the total oxygen amount increases especially for the intermediate fluences. In this calculation, we suppose that each germanium atom desorbs in the form of $\mathrm{GeO}$, carrying one oxygen atom while leaving the sample through the surface (orange boxes in figure 4). The amount of desorbing $\mathrm{GeO}$ molecules is deduced from Ge losses measured by RBS after annealing. NRA measurements will allow us to constrain the amount of ${ }^{18} \mathrm{O}$ in our RNRA fits. 
In Ge-implanted $\mathrm{SiO}_{2}$ layers, germanium mobility decreases as the fluence increases due to the formation of Ge-Si and Ge-Ge chemical bonds during implantation and annealing steps. Table I shows the decrease of Ge mobility, manifested by the reduction of the percentage of Ge in peaks 1 and 3, which obviously also depends of the relative distance with both interfaces.

${ }^{18} \mathrm{O}$ depth-profiles (blue solid lines) after annealing are superimposed on the Ge depth-profiles in figure 3 and fitted in figure 5 for each fluence. ${ }^{18} \mathrm{O}$ depth-profiles, shown in figure 5 , can be decomposed in three contributions (processes I, IIa and IIb).

As the whole diffusion process is complex with the simultaneous diffusion of multiple species occurring at different rates, we will propose a possible explanation based on our experimental observations and literature.

A significant ${ }^{18} \mathrm{O}$ surface peak, noted process $\mathrm{I}$, arises at the gas $/ \mathrm{SiO}_{2}$ interface and is attributed to the irradiation-induced damage and preferential sputtering of oxygen occurring at the sample surface during Ge implantation $[9,13,19,26]$. Process I depends on the implanted ions energy and fluence, with a tail which extends from 25 to $50 \mathrm{~nm}$. Therefore, a damaged oxygen-poor surface is exposed to ${ }^{18} \mathrm{O}_{2}$ during annealing, highly increasing the oxygen permeability of the surface [9]. Figure 5 shows that ${ }^{18} \mathrm{O}$ saturation is achieved at the extreme surface even for our low oxygen pressure. This surface will act as a constant oxygen provider.

Before annealing, the subsurface region is mainly composed of a mixture of partially oxidized silicon or germanium $\left(\mathrm{SiO}_{\mathrm{x}}\right.$ and $\mathrm{GeO}_{\mathrm{x}}$ with $\mathrm{x}<2$ ) and elemental $\mathrm{Ge}$ (chemically bound to $\mathrm{Ge}$ or $\mathrm{Si}$ ) whose concentration increases with the Ge fluence [17,26] (see two examples in figure $\mathrm{S} 2$ in supplementary material). At $1100^{\circ} \mathrm{C}, \mathrm{SiO}_{\mathrm{x}}$ is supposed to reduce within the first second of annealing [29] by equation 3. This agrees with Borodin et al. model [18], considering only $\mathrm{O}_{2}$ and the fraction of $\mathrm{Ge}$ which did not nucleate as the diffusing species. At the same time, ${ }^{18} \mathrm{O}_{2}$ penetrates the sample through the damaged surface and fully oxidizes all species present, or incoming, in the subsurface region, e.g. by reactions such as: 


$$
\begin{aligned}
& 2 \mathrm{GeO}+{ }^{18} \mathrm{O}_{2(g)} \rightarrow 2 \mathrm{GeO}_{2}, \\
& \mathrm{Ge}+{ }^{18} \mathrm{O}_{2(g)} \rightarrow \mathrm{GeO}_{2}, \\
& \mathrm{Si}+{ }^{18} \mathrm{O}_{2(g)} \rightarrow \mathrm{SiO}_{2} .
\end{aligned}
$$

At the temperature considered in this work $\left(1100^{\circ} \mathrm{C}\right)$, Ge and Si oxidation occurs at the same time. However, $\mathrm{SiO}_{2}$ is thermodynamically more stable than $\mathrm{GeO}_{2}$ in systems involving $\mathrm{Si}, \mathrm{Ge}$ and $\mathrm{O}$, for which $\mathrm{GeO}_{2}$ tends to reduce by reactions such as equation 2 in the presence of silicon even for weak $\mathrm{Si}$ concentrations [33]. Therefore, ${ }^{18} \mathrm{O}$ atoms will more favorably restore the $\mathrm{SiO}_{2}$ stoichiometry (equation 8) than form $\mathrm{GeO}_{2}$. This passivation of silicon dangling bonds also enhances the diffusion of germanium by limiting the formation of $\mathrm{Ge}-\mathrm{Si}$ bonds, favoring its desorption. RBS spectra show that germanium outward diffusion is initiated before its oxidation to immobile $\mathrm{GeO}_{2}$, leading to the formation of peak 1. XPS studies confirmed that peak 1 is composed of fully oxidized germanium $[9,11,12,26]$. Zatsepin et al. [26] showed that each germanium atom, implanted near the sample surface (in the first $30-35 \mathrm{~nm}$ ), is at least partially oxidized after 15 seconds of annealing at $950^{\circ} \mathrm{C}$, with a fraction of $\mathrm{GeO}_{2} / \mathrm{GeO}_{\mathrm{x}}(\mathrm{x}<2)$ which increases with the annealing time (approximately $40-45 \%$ of Ge is fully oxidized after 1 minute in these conditions). As the coefficients of diffusion increase with the temperature, the oxidation of germanium in the subsurface region will occur in a shorter time at $1100^{\circ} \mathrm{C}$.

Process I is fitted by an erfc function, resulting from the encounter of incompletely oxidized species and ${ }^{18} \mathrm{O}_{2}$ molecules [22]:

$$
\left[{ }^{18} O\right]_{I}(x, t)=\alpha \operatorname{erfc}(\beta x)
$$

where $\alpha$ is the maximum concentration at the sample surface, almost constant for all samples, and $\beta$ represents the dose-dependent peak width. $\beta=\frac{1}{2 \sqrt{D t}}$, with $D$ proportional to the 
concentration of incompletely oxidized species and their respective coefficient of diffusion. As shown in figure 3, peak 1 overlaps with the tail of the ${ }^{18} \mathrm{O}$ surface peak, confirming an encounter between the oxygen molecules present in the annealing atmosphere, penetrating $\mathrm{SiO}_{2}$ through the surface and diffusing inwards, and out-diffusing $\mathrm{GeO}_{\mathrm{x}}$ compounds close to the surface. This is consistent with other works [10-12], which suggested an overlapping between penetrating oxidizing agents and outgassing $\mathrm{GeO}$ leading to the formation of fixed $\mathrm{GeO}_{2}$ close to the sample surface.

Process IIa is hypothesized to be the result of the diffusion of ${ }^{18} \mathrm{O}_{2}$ molecules interacting with the Ge-implanted $\mathrm{Si}^{16} \mathrm{O}_{2}$ network. Process IIa is fitted using the following equation, presented in ref. [21]:

$$
\left[{ }^{18} O\right]_{I I a}(x, t)=L_{g}^{18}\left[{ }^{18} O\right]_{c, x=0} \frac{\cosh \left[\left(x-x_{0}\right) / \lambda\right]}{\cosh \left(x_{0} / \lambda\right)} \gamma t
$$

where $L_{g}^{18}$ is the isotopic labeling of the employed gas, $\left[{ }^{18} \mathrm{O}\right]_{c, x=0}$ is the oxygen concentration at the sample surface (depending of the ${ }^{18} \mathrm{O}$-enrichment and pressure of the gas and the solubility of ${ }^{18} \mathrm{O}$ in $\left.\mathrm{SiO}_{2}[34]\right), x_{0}$ is the oxide thickness, $\lambda$ is the characteristic ${ }^{16} \mathrm{O} /{ }^{18} \mathrm{O}$ exchange length and $\gamma$ is the average rate at which a diffusing oxygen atom is exchanged with an oxygen atom of the $\mathrm{Si}^{16} \mathrm{O}_{2}$ network.

Using $\lambda$ and $\gamma$ parameters, we are able to calculate the ${ }^{18} \mathrm{O}_{2}$ diffusion coefficient by the equation: $D_{O_{2}}=\gamma \lambda^{2} . \quad \lambda, \quad \gamma$ and $D_{O_{2}}$ values are summarized in table II for each sample. $D_{O_{2}}\left(1100^{\circ} \mathrm{C}\right) \sim 10^{-9} \mathrm{~cm}^{2} / \mathrm{s}$ is about one order of magnitude lower than the coefficient found by F. J. Norton in case of pure $\mathrm{SiO}_{2}$ layer [34]: $1.2 \times 10^{-9} \mathrm{~cm}^{2} / \mathrm{s}$ at $1078^{\circ} \mathrm{C}$. The difference could be explained by the morphological difference of our Ge-implanted samples compared to a pure $\mathrm{SiO}_{2}$ layer, probably increasing the interactions between $\mathrm{O}_{2}$ and the network. This is supported by the decreasing of $\lambda$ and $D_{O_{2}}$ with the increasing of Ge fluence (Table II). 
Process IIb, which is related to process IIa, is a buildup of inward diffusing ${ }^{18} \mathrm{O}$ whose integral and depth-position appear to be determined by the local concentration of $\mathrm{Ge}-\mathrm{Ge}$ and $\mathrm{Ge}-\mathrm{Si}$ chemical bonds, which dominates in peak 2 , i.e. the oxide region where nanoclustering occurs $[10,11]$. Table II shows that, as the ${ }^{74} \mathrm{Ge}$ fluence increases, ${ }^{18} \mathrm{O}$ is trapped close to the surface in larger quantities. This is due to the local concentration of not mobile $\mathrm{Ge}-\mathrm{Ge}$ and $\mathrm{Ge}-\mathrm{Si}$ chemical bonds (i.e. nanoclusters), which increases with the fluence until dominating the formation of $\mathrm{GeO}_{\mathrm{x}}$ compounds during the implantation, as demonstrated by XPS in ref. [17] (see figure S2 in supplementary material, two examples are shown for Ge fluences of 0.37 and $1.30 \times 10^{17}$ $\left.\mathrm{Ge} / \mathrm{cm}^{2}\right)$.

Process IIb is fitted by a gaussian curve, whose integral is fixed by the total number of ${ }^{18} \mathrm{O}$ atoms present in the sample from the NRA measurements.

Under pure $\mathrm{N}_{2}$, peak 2 (figure 3) corresponds to the region of nanoclustering, where mostly GeGe or Ge-Si chemical bonds are observed $[6-8,10,12,13,17]$. When an oxygen contamination is present in the annealing environment, XPS and TEM measurements showed that peak 2 is gradually oxidized and the edge of the Ge nanocrystals band shifts to a greater depth with annealing time. For sufficient annealing time and oxygen supply, the complete oxidation of Ge nanocrystals can be achieved $[11,12,18]$.

This is consistent with our observations, showing that inward diffusing ${ }^{18} \mathrm{O}_{2}$ molecules react with Ge-Ge and Ge-Si bonds as soon as their concentrations increase. For longer annealing time, process IIb should continue to gradually overlap peak 2 until its complete oxidation. However, the shift of peak 2 towards the sample surface and the changes in its shape compared to pure $\mathrm{N}_{2}$ annealing indicate that fixed $\mathrm{GeO}_{2}$ is not directly formed. Two mechanisms must be considered. Firstly, the presence of oxygen occupies Si dangling bonds, favoring Ge diffusion. Secondly, the formation of $\mathrm{GeO}_{2}$ locally depends on the relative amounts of oxygen and germanium. Oxygen arrives gradually from the sample surface, while the local concentration 


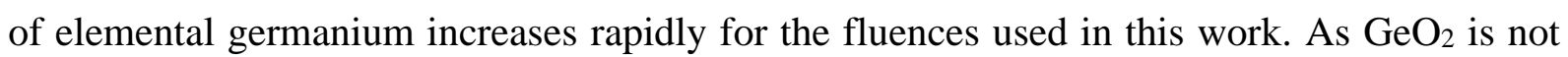
stable in the presence of germanium at high temperature $\left(\mathrm{GeO}_{2}+\mathrm{Ge} \rightarrow 2 \mathrm{GeO}\right)[33,35]$, a part of $\mathrm{GeO}$ molecules could diffuse towards the surface before being oxidized again in regions containing larger amounts of oxygen, either in peak 2 or near the sample surface (peak 1).

Considering the coefficient of diffusion deduced from process IIa, $D_{\mathrm{O}_{2}}\left(1100^{\circ} \mathrm{C}\right)$, the number of ${ }^{18} \mathrm{O}$ atoms at a certain depth $\Delta x$ after an annealing time $t$, maintaining a constant concentration of ${ }^{18} \mathrm{O}$ at the sample surface, is given by:

$$
n_{18} O(x, t)=\mathrm{L}_{\mathrm{g}}^{18}\left[{ }^{18} \mathrm{O}\right]_{C, x=0} D_{O_{2}}\left(1100^{\circ} \mathrm{C}\right) \frac{t}{\Delta x}
$$

This allows us to estimate the quantity of ${ }^{18} \mathrm{O}$ atoms which should accumulate by process IIb. As the integral of process IIb is systematically lower than this calculated value $n_{18}(x, t)$ for each sample, this supports the idea of an out-diffusion of $\mathrm{Ge}^{18} \mathrm{O}$, enhanced by the presence of oxygen in the annealing atmosphere.

Considering the weak isotopic labeling of the $\mathrm{SiO}_{2}$ layer after annealing, corresponding to less than $8 \%$ of the total oxygen amount, we assume that processes I and II are independent. No measurable ${ }^{18} \mathrm{O}$ accumulation has been observed at the $\mathrm{SiO}_{2} / \mathrm{Si}$ interface, indicating that all ${ }^{18} \mathrm{O}_{2}$ is consumed in Ge oxidation process of peak 2 . Therefore, peak 3, in the vicinity of the $\mathrm{SiO}_{2} / \mathrm{Si}$ interface, is rather more influenced by the oxide thickness and Ge fluence than the presence of ${ }^{18} \mathrm{O}$ in the annealing atmosphere. For a similar atomic concentration, Ge buildup at the interface is more significant for thinner samples (table I), which can be explained by the proximity to the $\mathrm{SiO}_{2} / \mathrm{Si}$ interface. 


\section{Conclusions}

We studied the origin of oxygen involved in germanium diffusion into a $\mathrm{SiO}_{2} / \mathrm{Si}$ layer, by a combination of stable isotopic tracing and three IBA techniques: RBS, RNRA and NRA.

A new experimental proof is provided that, compared to a pure $\mathrm{N}_{2}$ environment, a low percentage of $\mathrm{O}_{2}$ in the annealing atmosphere enhances $\mathrm{Ge}$ out-diffusion, through the formation of $\mathrm{GeO}$ molecules. It is shown that this oxygen contamination causes the oxidation of diffusing species close to the sample surface, as well as in the region of nanocrystals growth, in agreement with models proposed in literature. This underlines the importance of working in pure and nonreactive atmosphere.

\section{SUPPLEMENTARY MATERIAL}

See supplementary material for RBS analyses highlighting the changes in the $\mathrm{SiO}_{2}$ stoichiometry after the Ge implantation (figure S1). Figure $\mathrm{S} 2$ shows Ge depth-profiles in $\mathrm{SiO}_{2}$ measured by XPS for two different Ge fluences. The chemical state of implanted Ge ions after the implantation is shown in figure $\mathrm{S} 2$.

\section{ACKNOWLEDGMENTS}

This work was made possible thanks to the Fédération Wallonie-Bruxelles (FWB) travel grant (BV17-54). The authors would like to thank SIAM (Synthesis, Irradiation and Analysis of Materials) technological platform for the use of ALTAÏS and T. Tabarrant for his technical support on the accelerator. This work had benefitted from access to the SAFIR platform of the CNRS and Sorbonne University. A.N. would like to personnaly thank Hervé Tancrez.

\section{DATA AVAILABILITY}

The data that support the findings of this study are available from the corresponding author upon request. 


\section{REFERENCES}

[1] Green, M. A., Bremner, S. P. (2017). Energy conversion approaches and materials for high-efficiency photovoltaics. Nature Materials, 16, 23-34. https://doi.org/10.1038/nmat4676

[2] Yedji, M., Demarche, J., Terwagne, G., Delamare, R., Flandre, D., Barba, D., Koshel, D., Ross, G. G. (2011). Method for fabricating third generation photovoltaic cells based on Si quantum dots using ion implantation into SiO2. J. Appl. Phys., 109(8), 084337. https://doi.org/10.1063/1.3575325

[3] Beard, M. C., Knustsen, K. P., Yu, P., Song, Q., Luther, J., Ellingson, R., Nozik, A. J. (2007). Multiple exciton generation in colloidal silicon nanocrystals. Nano Lett., 7, 2506-2512. https://doi.org/10.1021/n10714861

[4] Trinh, M. T., Limpens, R., de Boer, W. D. A. M., Schins, J. M., Siebbeles, L. D. A., Gregorkiewicz, T. (2012). Direct generation of multiple excitons in adjacent silicon nanocrystals revealed by induced absorption. Nature Photonics, 6(5), 316-321. https://doi.org/10.1038/nphoton.2012.36

[5] Smith, C., Binks, D. (2013). Multiple Exciton Generation in Colloidal Nanocrystals. Nanomaterials, 4(1), 19-45. https://doi.org/10.3390/nano4010019

[6] Barba, D., Wang, C., Nélis, A., Terwagne, G., Rosei, F. (2018). Blocking germanium diffusion inside silicon dioxide using a co-implanted silicon barrier. J. Appl. Phys., 123(16), 161540. https://doi.org/10.1063/1.5002693

[7] Nélis, A., Barba, D., Terwagne, G. (2020). Control of germanium diffusion using low quantities of co-implanted silicon isotopes. J. Appl. Phys., 128(12), 125705. https://doi.org/10.1063/5.0020368

[8] Markwitz, A., Schmidt, B., Matz, W., Grötzschel, R., Mücklich, A. (1998). Microstructural investigation of ion beam synthesised germanium nanoclusters embedded in SiO2 layers. Nucl. Instrum. Methods Phys. Res. B, 142(3), 338-348. https://doi.org/10.1016/S0168-583X(98)00283-3

[9] Beyer, V., von Borany, J. (2008). Elemental redistribution and Ge loss during ion-beam synthesis of Ge nanocrystals in SiO2 films. Phys. Rev. B, 77(1), 014107. https://doi.org/10.1103/PhysRevB.77.014107

[10] von Borany, J., Grötzschel, R., Heinig, K. H., Markwitz, A., Matz, W., Schmidt, B., Skorupa, W. (1997). Multimodal impurity redistribution and nanocluster formation in Ge implanted silicon dioxide films. Appl. Phys. Lett., 71(22), 3215-3217. https://doi.org/10.1063/1.120294

[11] Heinig, K. H., Schmidt, B., Markwitz, A., Grötzschel, R., Strobel, M., Oswald, S. (1999). Precipitation, ripening and chemical effects during annealing of Ge+ implanted $\mathrm{SiO} 2$ layers. Nucl. Instrum. Methods Phys. Res. B, 148(1-4), 969-974. https://doi.org/10.1016/S0168-583X(98)00862-3 
[12] Oswald, S., Schmidt, B., Heinig, K.-H. (2000). XPS investigation with factor analysis for the study of Ge clustering in SiO2. Surf. Interface Anal., 29(4), 249-254. https://doi.org/10.1002/(SICI)1096-9918(200004)29:4<249::AID-SIA735>3.0.CO;2-5

[13] Barba, D., Cai, R. S., Demarche, J., Wang, Y. Q., Terwagne, G., Rosei, F., Ross, G. G. (2014). Influence of silicon dangling bonds on germanium thermal diffusion within SiO2 glass. Appl. Phys. Lett., 104(11), 111901. https://doi.org/10.1063/1.4868721

[14] Baranwal, V., Gerlach, J. W., Lotnyk, A., Rauschenbach, B., Karl, H., Ojha, S., Avasthi, D. K., Kanjilal, D., Pandey, A. C. (2015). Embedded Ge nanocrystals in SiO2 synthesized by ion implantation. J. Appl. Phys., 118(13), 134303. https://doi.org/10.1063/1.4932151

[15] Uematsu, M., Kageshima, H., Takahashi, Y., Fukatsu, S., Itoh, K. M., Shiraishi, K., Gösele, U. (2004). Modeling of Si self-diffusion in SiO2: Effect of the Si/SiO2 interface including time-dependent diffusivity. Appl. Phys. Lett., 84(6), 876-878. https://doi.org/10.1063/1.1644623

[16] Choi, W. K., Ho, V., Ng, V., Ho, Y. W., Ng, S. P., Chim, W. K. (2005). Germanium diffusion and nanocrystal formation in silicon oxide on silicon substrate under rapid thermal annealing. Appl. Phys. Lett., 86(14), 1-3. https://doi.org/10.1063/1.1891290

[17] Nélis, A., Haye, E., Terwagne, G. (2021). Influence of oxygen co-implantation on germanium out-diffusion and nanoclustering in SiO2/Si films. (To be published)

[18] Borodin, V. A., Heinig, K. H., Schmidt, B. (1999). Modeling of Ge nanocluster evolution in ion-implanted SiO2 layer. Nucl. Instrum. Methods Phys. Res. B, 147(1-4), 286-291. https://doi.org/10.1016/S0168-583X(98)00562-X

[19] Ziegler, J. F., Ziegler, M. D., Biersack, J. P. (2010). SRIM - The stopping and range of ions in matter (2010). Nucl. Instrum. Methods Phys. Res. B, 268(11-12), 1818-1823. https://doi.org/10.1016/j.nimb.2010.02.091

[20] Amsel, G., Samuel, D. (1967). Microanalysis of the Stable Isotopes of Oxygen by Means of Nuclear Reactions. Anal. Chem., 39(14), 1689-1698. https://doi.org/10.1021/ac50157a027

[21] Cavellin, C. D., Trimaille, I., Ganem, J. J., D’Angelo, M., Vickridge, I., Pongracz, A., Battistig, G. (2009). An 180 study of the interaction between carbon monoxide and dry thermal SiO2 at $1100{ }^{\circ} \mathrm{C}$. J. Appl. Phys., 105(3), 1-7. https://doi.org/10.1063/1.3072679

[22] Trimaille, I., Rigo, S. (1989). Use of 180 isotopic labelling to study thermal dry oxidation of silicon as a function of temperature and pressure. Appl. Surf. Sci., 39(1-4), 65-80. https://doi.org/10.1016/0169-4332(89)90420-0

[23] Battistig, G., Amsel, G., d'Artemare, E., Vickridge, I. (1991). A very narrow resonance in $180(p, \alpha) 15 N$ near $150 \mathrm{keV}$ : Application to isotopic tracing. I. Resonance width measurement. Nucl. Instrum. Methods Phys. Res. B, 61(4), 369-376. https://doi.org/10.1016/0168-583X(91)95308-Z 
[24] Vickridge, I., Amsel, G. (1990). SPACES: A PC implementation of the stochastic theory of energy loss for narrow-resonance depth profiling. Nucl. Instrum. Methods Phys. Res. B, 45(1-4), 6-11. https://doi.org/10.1016/0168-583X(90)90772-M

[25] Ganem, J.-J., Trimaille, I., André, P., Rigo, S., Stedile, F. C., Baumvol, I. J. R. (1997). Diffusion of near surface defects during the thermal oxidation of silicon. J. Appl. Phys., 81(12), 8109-8111. https://doi.org/10.1063/1.365420

[26] Zatsepin, A. F., Zatsepin, D. A., Zhidkov, I. S., Kurmaev, E. Z., Fitting, H. J., Schmidt, B., Mikhailovich, A.P., Lawniczak-Jablonska, K. (2015). Formation of Ge $O$ and $\mathrm{GeO} x$ nanoclusters in $\mathrm{Ge}+$-implanted $\mathrm{SiO} 2 \mathrm{Si}$ thin-film heterostructures under rapid thermal annealing. Appl. Surf. Sci., 349, 780-784. https://doi.org/10.1016/j.apsusc.2015.05.090

[27] Minke, M. V., Jackson, K. A. (2005). Diffusion of germanium in silica glass. J. NonCrystalline Solids, 351(27-29), 2310-2316. https://doi.org/10.1016/j.jnoncrysol.2005.04.052

[28] Gambaryan, M. P., Krivyakin, G. K., Cherkova, S. G., Stoffel, M., Rinnert, H., Vergnat, M., Volodin, V. A. (2020). Quantum Size Effects in Germanium Nanocrystals and Amorphous Nanoclusters in GeSixOy Films. Phys. Solid State, 62(3), 492-498. https://doi.org/10.1134/S1063783420030105

[29] Dan'ko, V. A. (2005). Kinetics of Structural and Phase Transformations in Thin SiOx Films in the Course of a Rapid Thermal Annealing. Semiconductors, 39(10), 1197. https://doi.org/10.1134/1.2085270

[30] Prabhakaran, K., Maeda, F., Watanabe, Y., Ogino, T. (2000). Distinctly different thermal decomposition pathways of ultrathin oxide layer on Ge and Si surfaces. Appl. Phys. Lett., 76(16), 2244-2246. https://doi.org/10.1063/1.126309

[31] Barba, D., Demarche, J., Martin, F., Terwagne, G., Ross, G. G. (2012). Trapping of diffusing germanium by silicon excess co-implanted into fused silica. Appl. Phys. Lett., 101(14), 143107. https://doi.org/10.1063/1.4757291

[32] Takakuwa, Y., Nihei, M., Miyamoto, N. (1993). Outdiffusion and Subsequent Desorption of Volatile SiO Molecules during Annealing of Thick SiO2 Films in Vacuum. Jpn J. Appl. Phys., 32(Part 2, No. 4A), L480-L483. https://doi.org/10.1143/JJAP.32.L480

[33] Hellberg, P.-E., Zhang, S.-L., D’Heurle, F. M., Petersson, C. S. (1997). Oxidation of silicon-germanium alloys. II. A mathematical model. J. Appl. Phys., 82(11), 5779-5787. https://doi.org/10.1063/1.366444

[34] Norton, F. J. (1961). Permeation of Gaseous Oxygen through Vitreous Silica. Nature, 191(4789), 701-701. https://doi.org/10.1038/191701a0

[35] Oh, J., Campbell, J. C. (2004). Thermal desorption of Ge native oxides and loss of Ge from the surface. J. Electon. Mater., 33(4), 364-367. https://doi.org/10.1016/j.mssp.2010.10.009 


\section{LIST OF FIGURES}

Figure 1. ${ }^{18} \mathrm{O}$ depth-distributions of $245 \mathrm{~nm} \mathrm{Si}{ }^{16} \mathrm{O} / \mathrm{Si}^{18} \mathrm{O} / \mathrm{Si}{ }^{16} \mathrm{O} / \mathrm{Si}$ layers for virgin oxide (solid line) and for implantation doses of $6.5 \times 10^{16}, 1.5 \times 10^{17}$ and $2.6 \times 10^{17} \mathrm{Ge} / \mathrm{cm}^{2}$. All profiles have as reference the $\mathrm{SiO}_{2} / \mathrm{Si}$ interface.

Figure 2. ${ }^{74} \mathrm{Ge}$ depth-profiles, extracted from RBS spectra, before (red crosses) and after (black dots) annealing and ${ }^{18} \mathrm{O}$ RNRA depth-profiles before (blue dashed line) and after (blue solid line) annealing for (a) $6.5 \times 10^{16}$, (b) $1 \times 10^{17}$ and (c) $1.5 \times 10^{17} \mathrm{Ge} / \mathrm{cm}^{2}$. The depth position of the main peak is spotted by a dotted line.

Figure 3. ${ }^{74} \mathrm{Ge}$ depth-profiles, extracted from RBS spectra, before (red crosses) and after (black dots) annealing, ${ }^{18} \mathrm{O}$ RNRA deconvoluted depth-profiles after annealing (blue solid line) and dpa calculated by SRIM-TRIM code (open squares), for fluencies of (a) $3.5 \times 10^{16}$, (b) $4.5 \times$ $10^{16}$, (c) $1.2 \times 10^{17}$ and (d) $2.2 \times 10^{17} \mathrm{Ge} / \mathrm{cm}^{2}$.

Figure 4. Total oxygen atoms measured by ${ }^{16} \mathrm{O}(\mathrm{d}, \alpha){ }^{14} \mathrm{~N}$ and ${ }^{18} \mathrm{O}(\mathrm{d}, \alpha){ }^{16} \mathrm{~N}$ reactions for $200 \mathrm{~nm}$ (left) and $300 \mathrm{~nm}$ (right) $\mathrm{SiO}_{2}$ before and after annealing. Orange boxes represent $\mathrm{GeO}$ desorption.

Figure 5. Measured (dots) and calculated with processes I, IIa and IIb (lines) ${ }^{18} \mathrm{O}$ RNRA depthprofiles for fluencies of (a) $3.5 \times 10^{16}$, (b) $4.5 \times 10^{16}$, (c) $1.2 \times 10^{17}$ and (d) $2.2 \times 10^{17} \mathrm{Ge} / \mathrm{cm}^{2}$. 


\section{FIGURES}

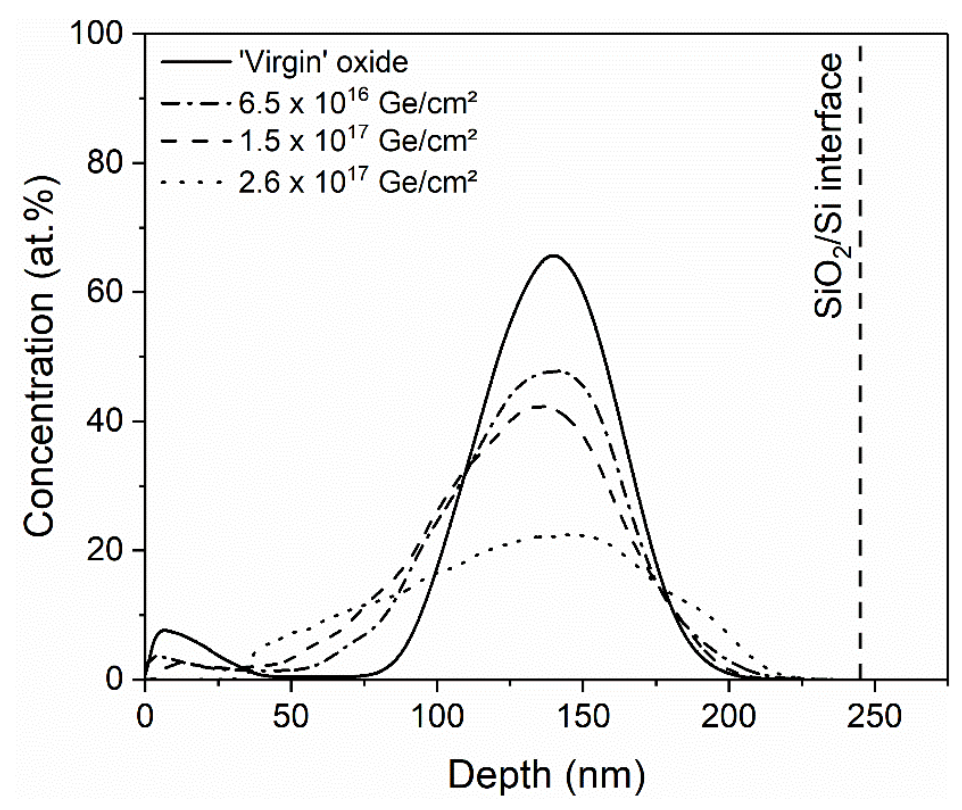

Figure 1.
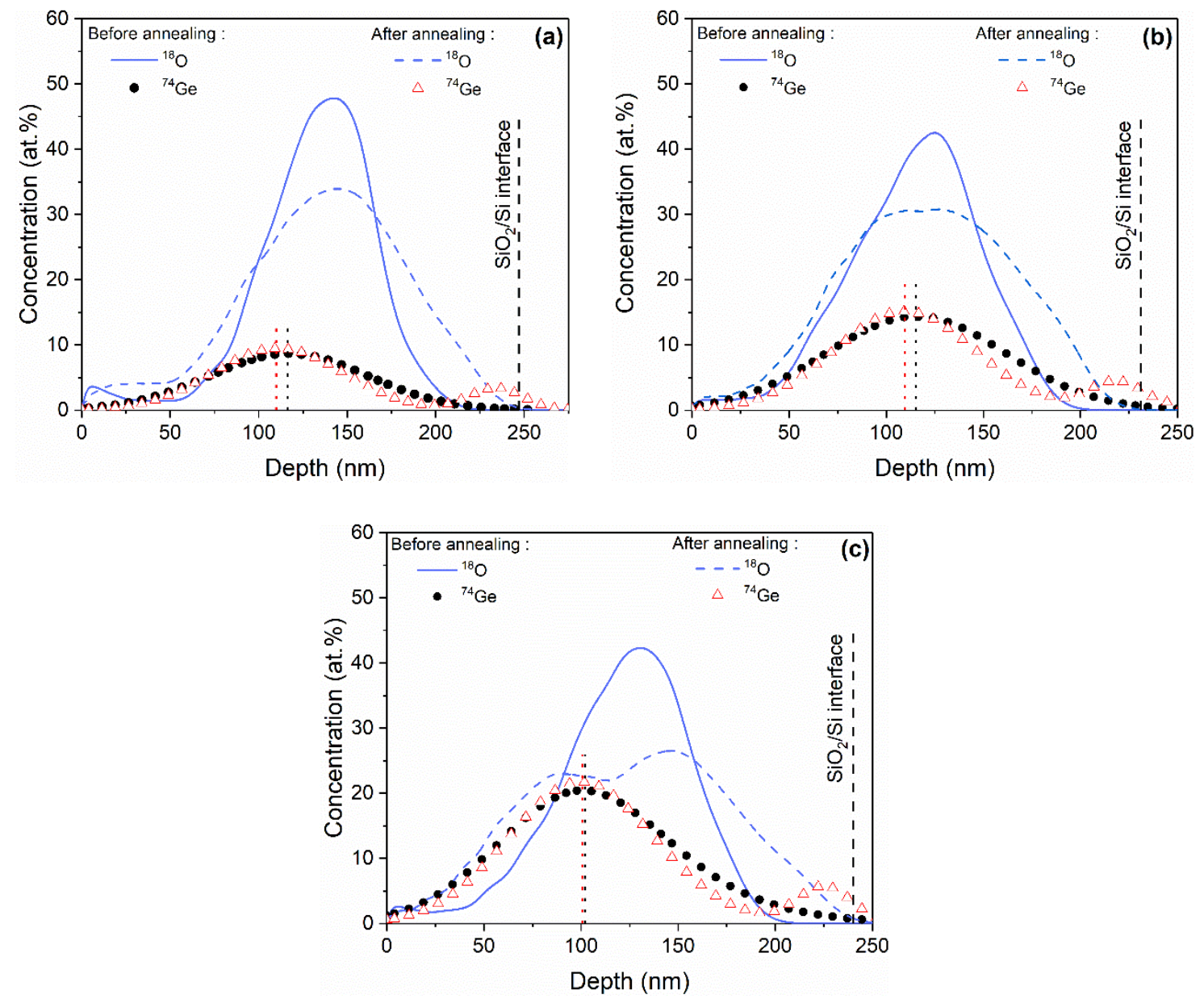

Figure 2. 

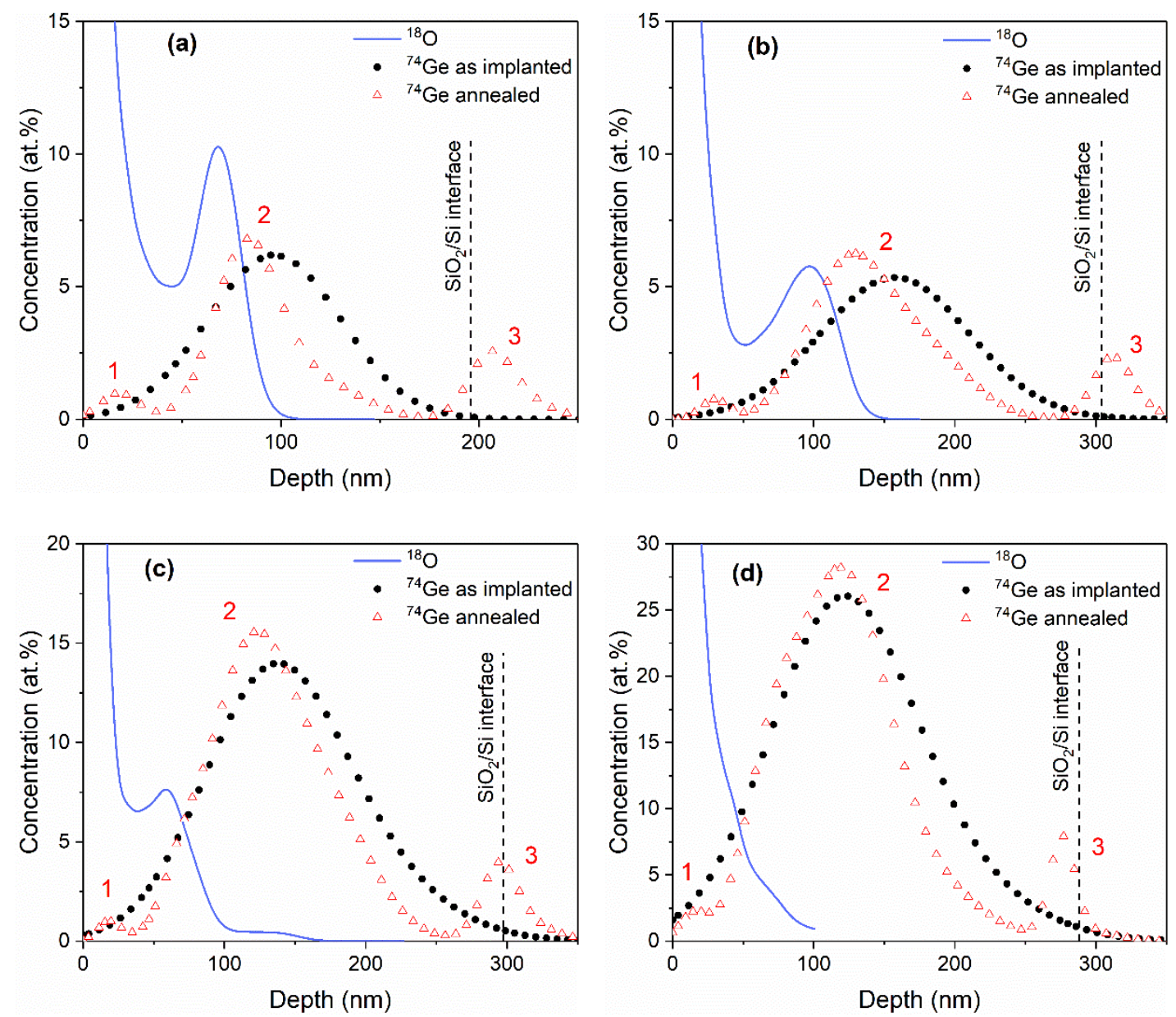

Figure 3.

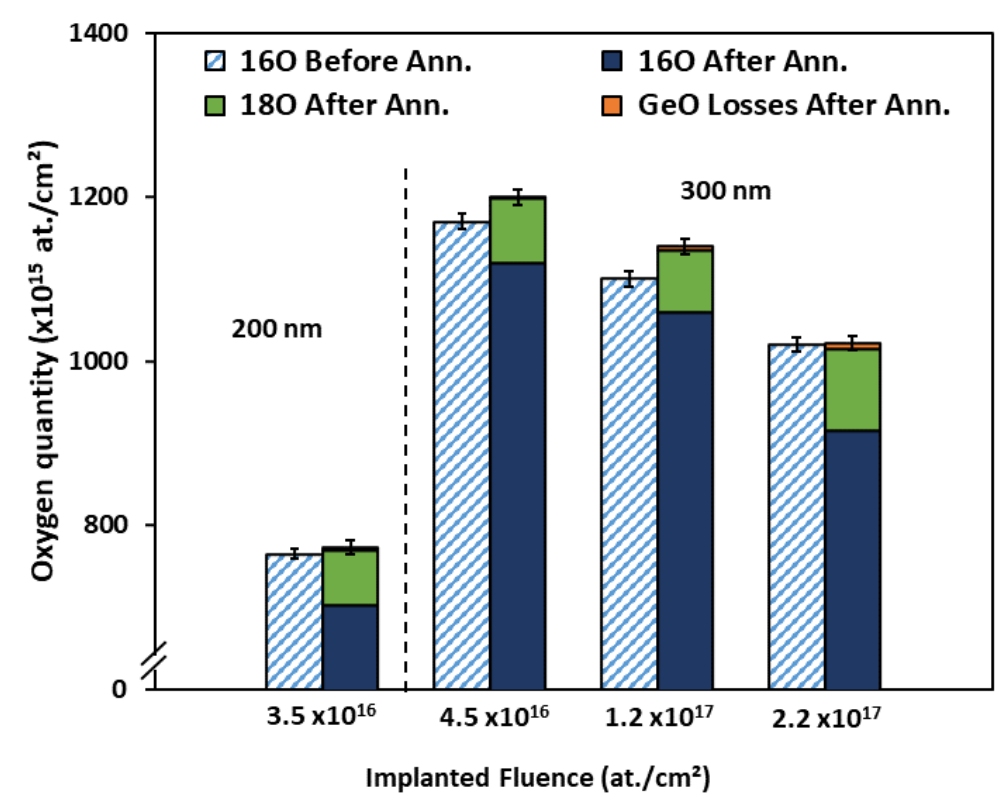

Figure 4. 

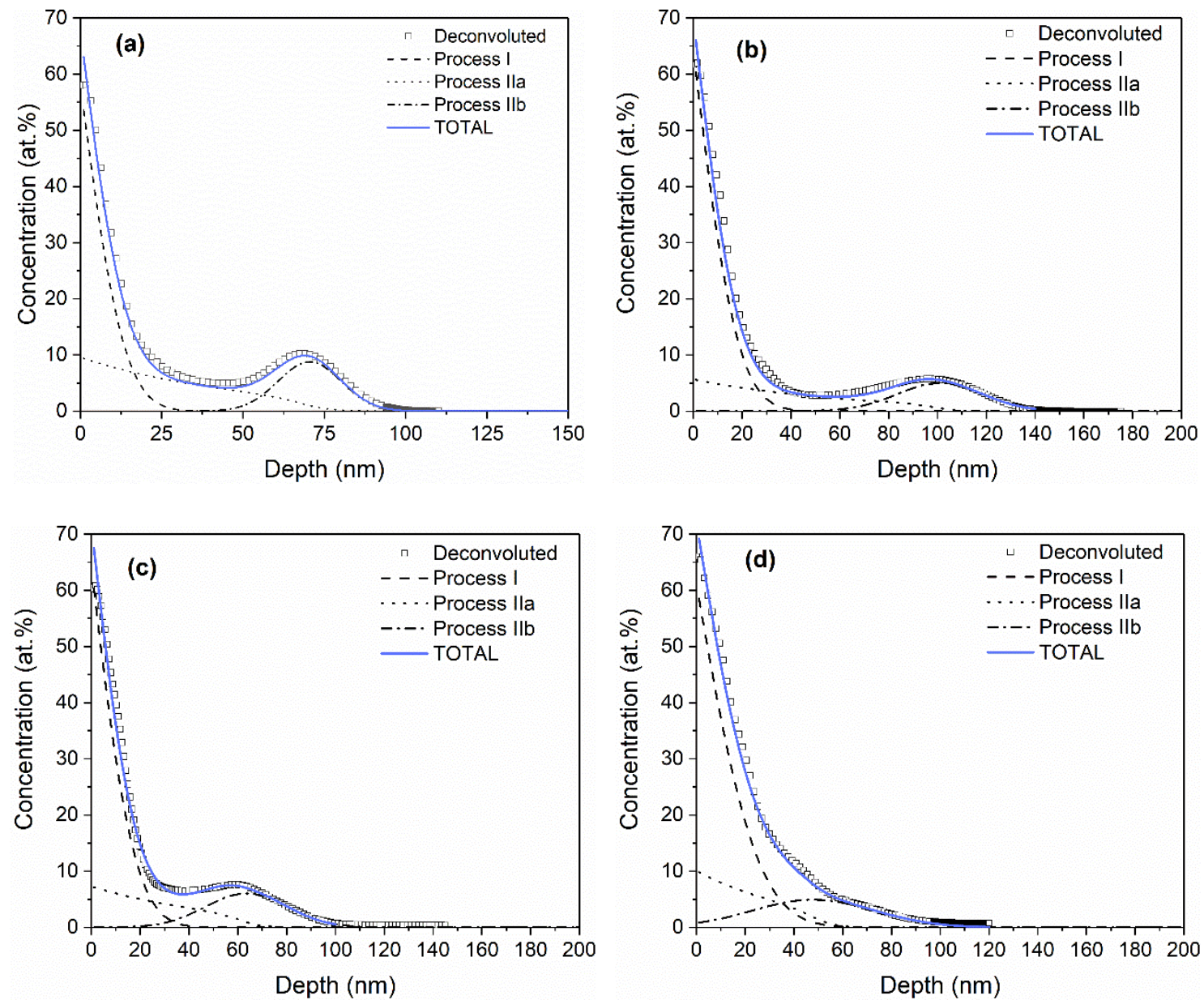

Figure 5. 


\section{LIST OF TABLES}

Table I. Percentage of Ge losses and contained in peaks 1 and 3 of figure 3 derived from RBS spectra, and maximum displacement per atom as calculated by TRIM.

Table II. Summarize of integrals for processes I, IIa and IIb, with fitting parameters and calculated coefficient of diffusion.

\section{TABLES}

\begin{tabular}{ccccc}
\hline $\begin{array}{c}\text { Fluence } \\
\left(\times 10^{16} \mathrm{Ge}^{\mathrm{c}} \mathrm{cm}^{2}\right)\end{array}$ & $\begin{array}{c}\text { Ge } \\
\text { Losses } \\
(\%)\end{array}$ & $\begin{array}{c}\text { Ge } \\
\text { peak 1 } \\
(\%)\end{array}$ & $\begin{array}{c}\text { Ge } \\
\text { peak 3 } \\
(\%)\end{array}$ & $\begin{array}{c}\text { Maximum displacement } \\
\text { per atom } \\
(\text { dpa })\end{array}$ \\
\hline 3.5 & 12 & 6.4 & 19 & 55 \\
4.5 & 2.5 & 3.7 & 14.4 & 72 \\
12 & 4.2 & 1.4 & 9.6 & 199 \\
22 & 2.7 & 1.5 & 7.9 & 366 \\
\hline
\end{tabular}

Table I.

\begin{tabular}{|c|c|c|c|c|c|c|c|c|}
\hline \multirow{2}{*}{$\begin{array}{c}\text { Fluence } \\
\left(\times \mathbf{1 0}^{16} \mathrm{Ge} / \mathrm{cm}^{2}\right)\end{array}$} & \multirow{2}{*}{$\begin{array}{c}\text { Ox. } \\
\text { Thick. } \\
\text { (nm) }\end{array}$} & \multirow{2}{*}{$\frac{\text { Process I }}{\sum_{\mathrm{I}}}$} & \multicolumn{4}{|c|}{ Process IIa } & \multicolumn{2}{|c|}{ Process IIb } \\
\hline & & & $\begin{array}{c}\lambda \\
(\mathbf{n m})\end{array}$ & $\begin{array}{c}\gamma \\
\left(s^{-1}\right)\end{array}$ & $\begin{array}{c}D_{o_{2}} \\
\left(\mathrm{~cm}^{2} / \mathbf{s}\right)\end{array}$ & $\begin{array}{c}\sum_{\mathrm{IIa}} \\
\left(\text { at. } / \mathbf{c m}^{2}\right)\end{array}$ & $\begin{array}{c}\sum_{\mathrm{IIb}} \\
\left(\mathbf{a t} . / \mathbf{c m}^{2}\right)\end{array}$ & $\begin{array}{c}\mathbf{x}_{\mathbf{C}} \\
(\mathbf{n m})\end{array}$ \\
\hline 3.5 & 200 & $3.06 \times 10^{16}$ & 50 & 59 & $1.48 \times 10^{-9}$ & $2.34 \times 10^{16}$ & $1.43 \times 10^{16}$ & 70.5 \\
\hline 4.5 & 300 & $4.59 \times 10^{16}$ & 65 & 35 & $1.48 \times 10^{-9}$ & $1.91 \times 10^{16}$ & $1.46 \times 10^{16}$ & 101.0 \\
\hline 12 & 300 & $4.50 \times 10^{16}$ & 50 & 49 & $1.31 \times 10^{-9}$ & $1.76 \times 10^{16}$ & $1.69 \times 10^{16}$ & 63.5 \\
\hline 22 & 300 & $6.15 \times 10^{16}$ & 43 & 62 & $1.15 \times 10^{-9}$ & $1.90 \times 10^{16}$ & $2.00 \times 10^{16}$ & 48.0 \\
\hline
\end{tabular}

Table II. 


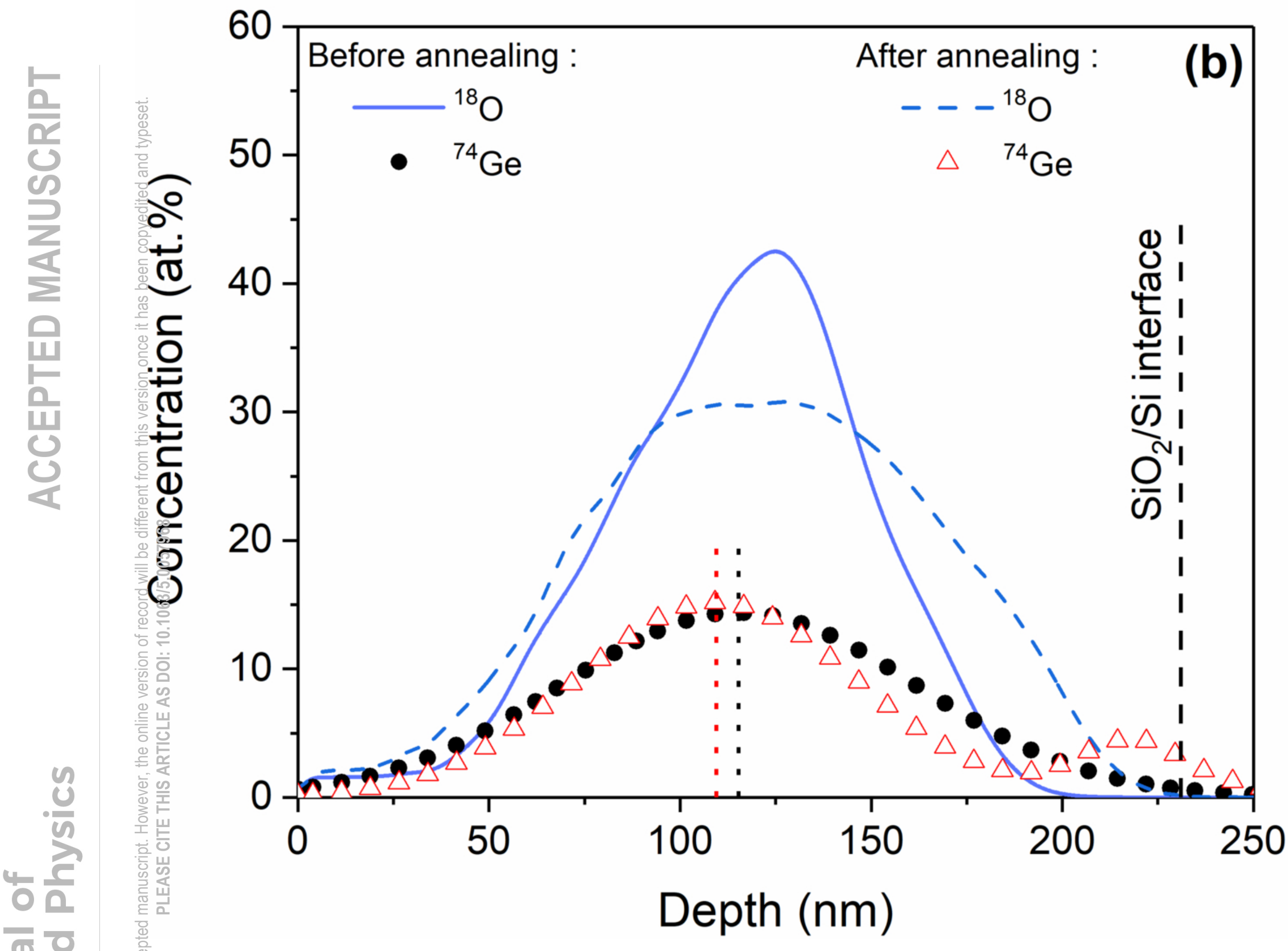




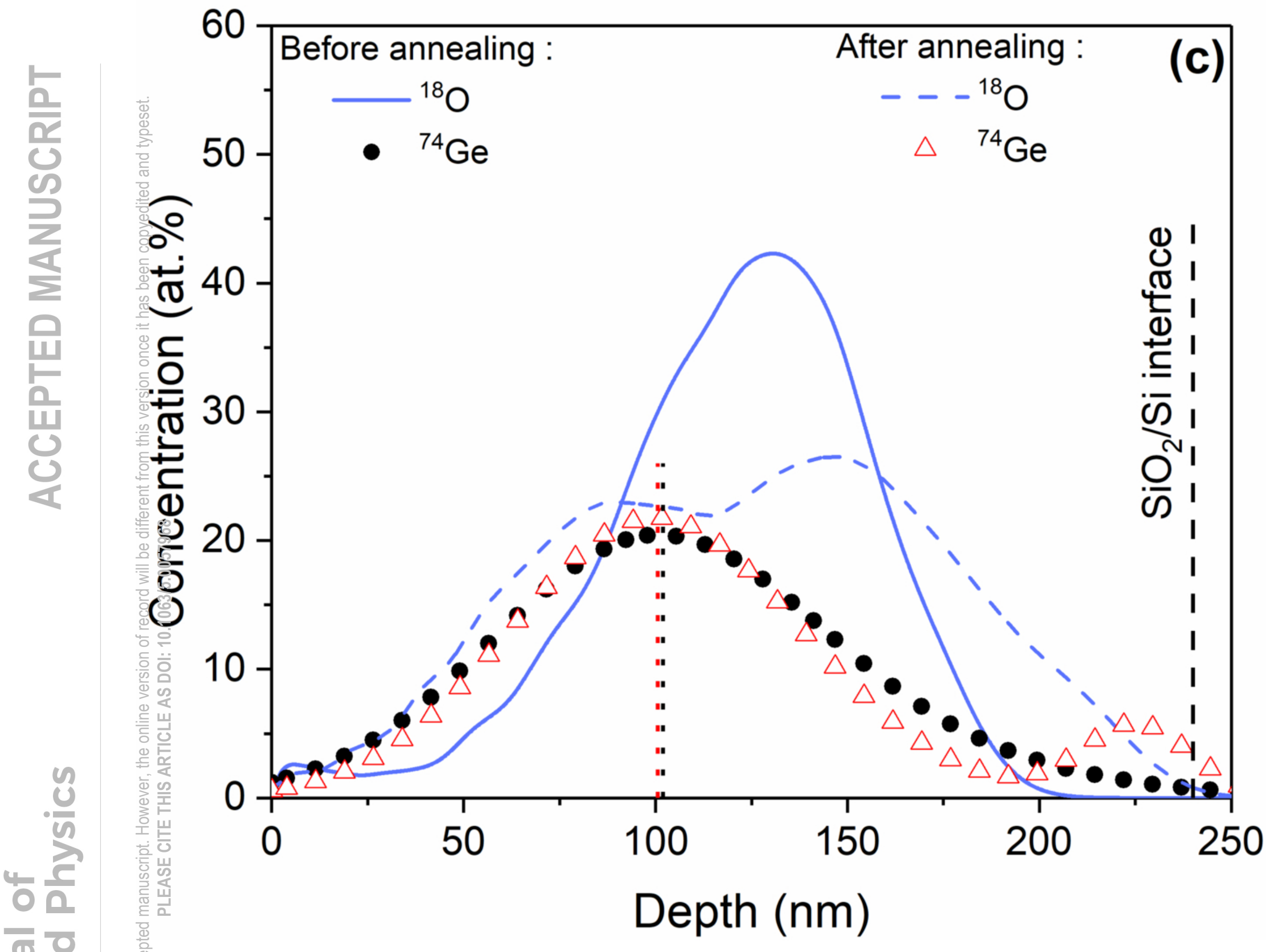




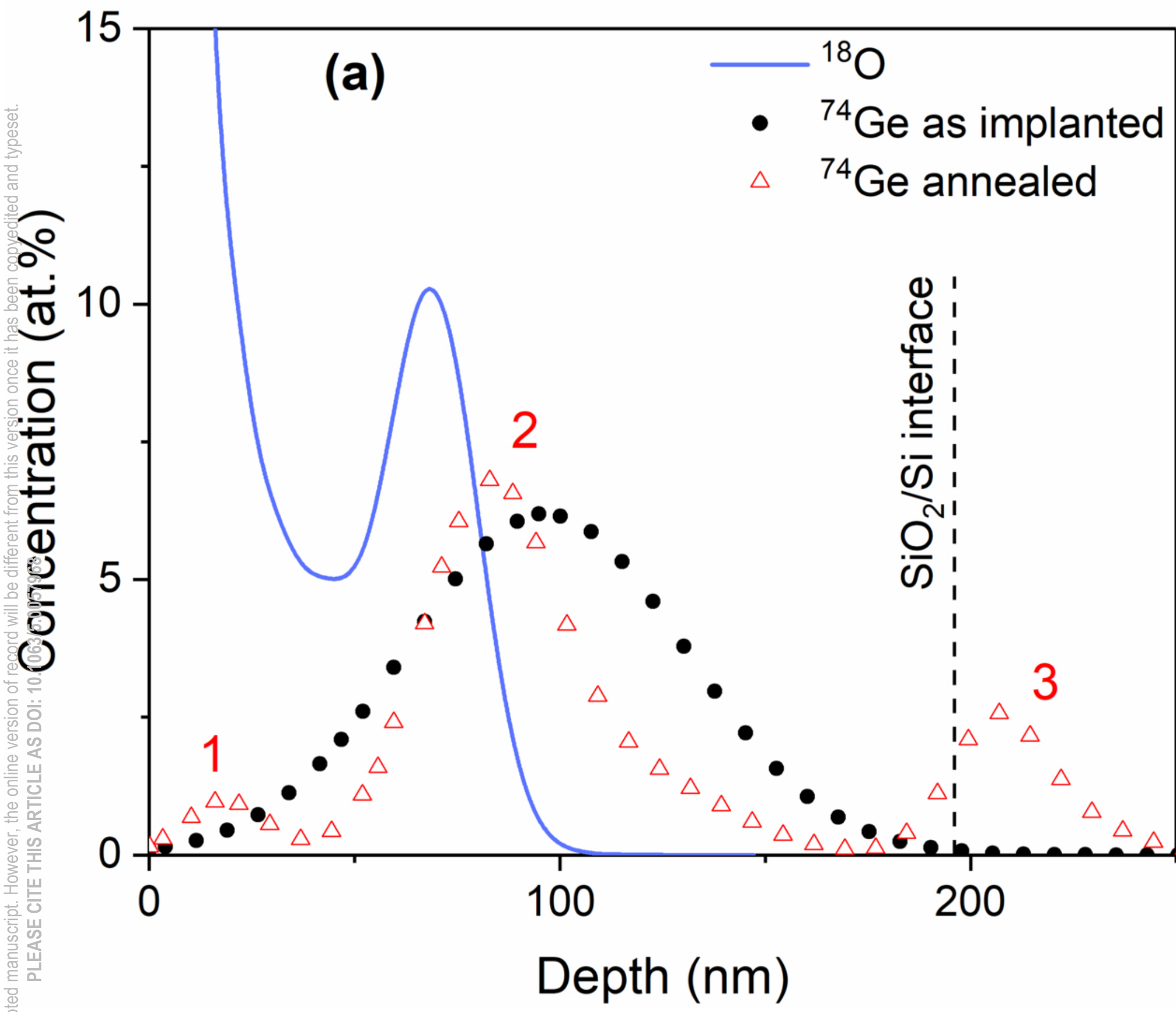




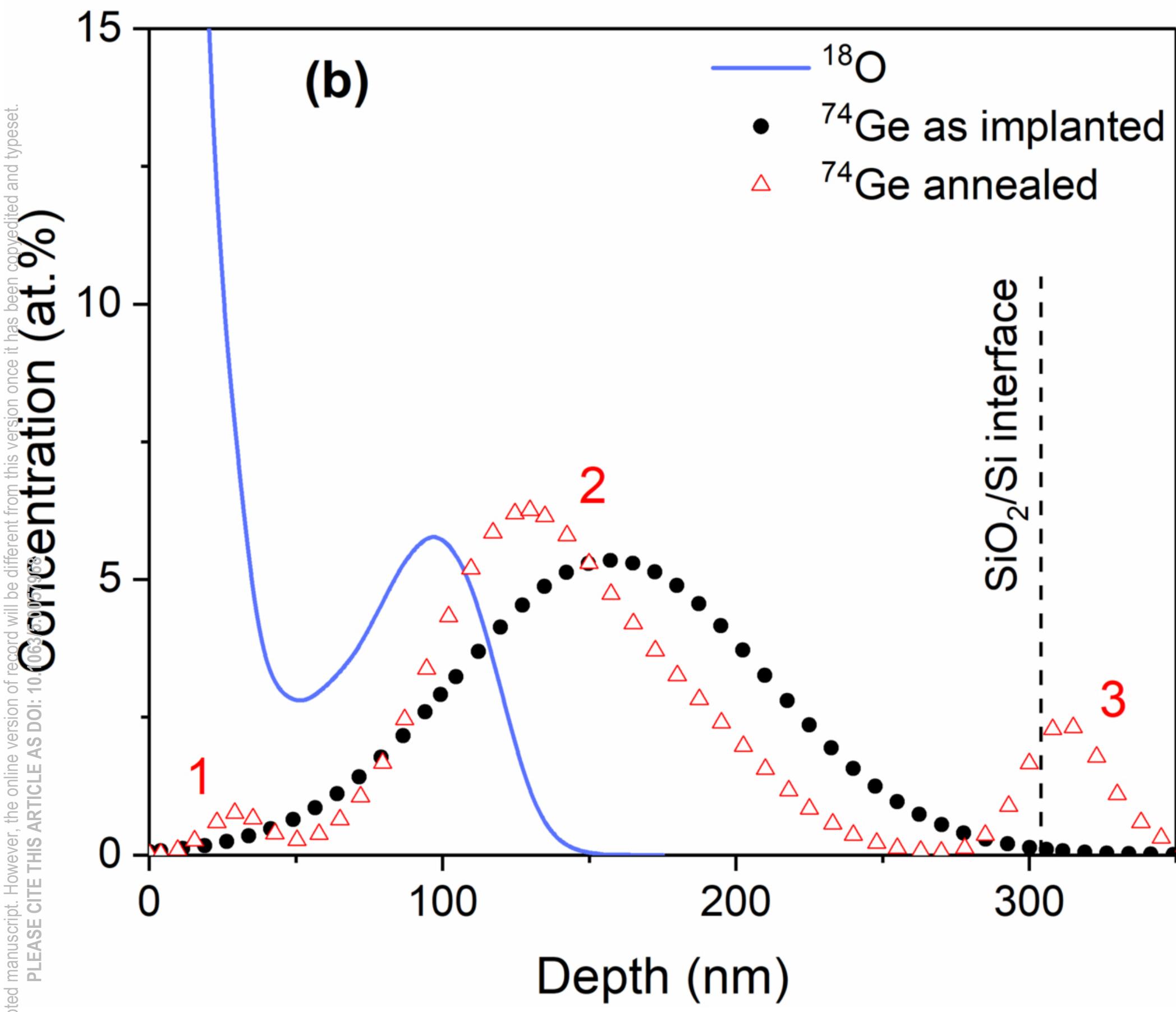




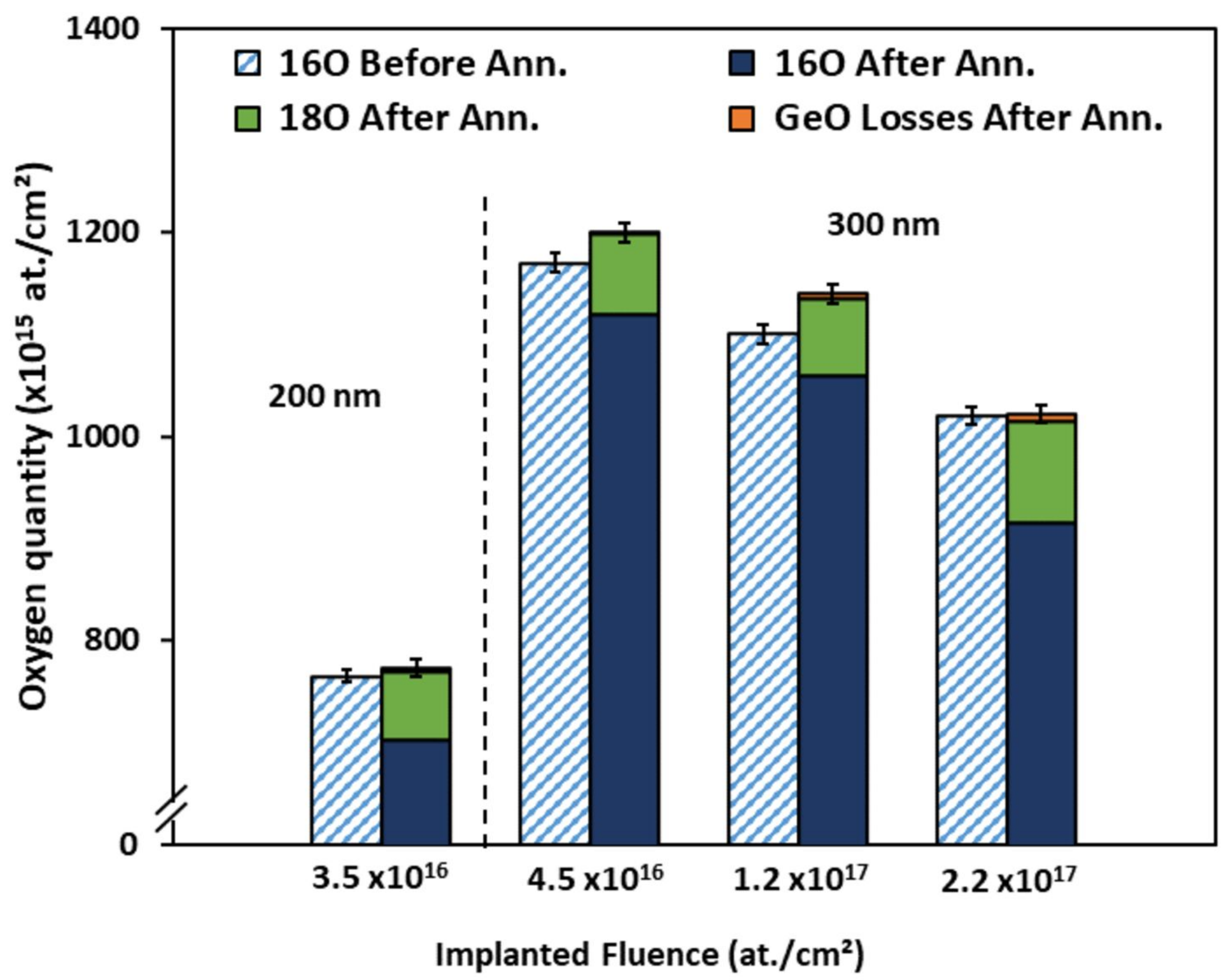


